\title{
Serotonergic Raphe Neurons Express TASK Channel Transcripts and a TASK-Like pH- and Halothane-Sensitive $\mathrm{K}^{+}$Conductance
}

\author{
Christopher P. Washburn, ${ }^{\star}$ Jay E. Sirois, ${ }^{*}$ Edmund M. Talley, Patrice G. Guyenet, and Douglas A. Bayliss \\ Department of Pharmacology, University of Virginia, Charlottesville, Virginia 22908
}

The recently described two-pore-domain $\mathrm{K}^{+}$channels, TASK-1 and TASK-3, generate currents with a unique set of properties; specifically, the channels produce instantaneous open-rectifier (i.e., "leak") $\mathrm{K}^{+}$currents that are modulated by extracellular $\mathrm{pH}$ and by clinically useful anesthetics. In this study, we used histochemical and in vitro electrophysiological approaches to determine that TASK channels are expressed in serotonergic raphe neurons and to show that they confer a $\mathrm{pH}$ and anesthetic sensitivity to these neurons. By combining in situ hybridization for TASK-1 or TASK-3 with immunohistochemical localization of tryptophan hydroxylase, we found that a majority of serotonergic neurons in both dorsal and caudal raphe cell groups contain TASK channel transcripts ( 70-90\%). Wholecell voltage-clamp recordings were obtained from raphe cells that responded to 5-HT in a manner characteristic of serotonergic neurons (i.e., with activation of an inwardly rectifying $\mathrm{K}^{+}$ current). In those cells, we isolated an endogenous $\mathrm{K}^{+}$conductance that had properties expected of TASK channel currents; raphe neurons expressed a joint $\mathrm{pH}$ - and halothanesensitive open-rectifier $\mathrm{K}^{+}$current. The $\mathrm{pH}$ sensitivity of this current ( $\mathrm{pK} \sim 7.0$ ) was intermediate between that of TASK-1 and TASK-3, consistent with functional expression of both channel types. Together, these data indicate that TASK-1 and TASK-3 are expressed and functional in serotonergic raphe neurons. The $\mathrm{pH}$-dependent inhibition of TASK channels in raphe neurons may contribute to ventilatory and arousal reflexes associated with extracellular acidosis; on the other hand, activation of raphe neuronal TASK channels by volatile anesthetics could play a role in their immobilizing and sedative-hypnotic effects.

Key words: rat; KCNK; acidosis; anesthetic; hybridization; 5-HT
The resting membrane potential and input resistance of neurons are key determinants of neuronal excitability; these intrinsic properties are determined, in large part, by constitutive activity of $\mathrm{K}^{+}$ selective channels. In recent years, a novel gene family of background $\mathrm{K}^{+}$channels has been identified, members of which have characteristics that are distinctly different from most other $\mathrm{K}^{+}$ channels and consistent with a role in setting membrane potential and input resistance (e.g., weak voltage dependence, extremely fast kinetics, etc.) (for review, see Lesage and Lazdunski, 2000; Goldstein et al., 2001; Patel and Honore, 2001; Patel et al., 2001). Although these so-called KCNK channels generally show some degree of background activity at normal resting potentials, they are nevertheless also subject to modulation by numerous factors. For example, channel activity is influenced by prevailing physicochemical conditions such as temperature, intracellular or extracellular $\mathrm{pH}$, oxygen tension, and membrane stretch and can be modulated by neurotransmitters, bioactive lipids, and anesthetics (Lesage and Lazdunski, 2000; Goldstein et al., 2001; Patel and Honore, 2001; Patel et al., 2001). Thus, the intrinsic properties conferred by these channels are not fixed, and their modulation can have dramatic effects on neuronal excitability.

The TASK subgroup of KCNK channels currently comprises

Received Oct. 1, 2001; revised Dec. 4, 2001; accepted Dec. 6, 2001.

This work was supported by National Institutes of Health Grants F32HL10271 (J.E.S.), F31MH12091 (E.M.T.), HL28785 (P.G.G.), and NS33583 (D.A.B.). We thank Drs. R. L. Stornetta and A. M. Schreihofer for help with the dual-labeling procedures and Dr. C. Lynch for helpful discussions. We also thank Drs. A. T. Gray and D. Kim for gifts of TASK channel cDNAs.

*C.P.W. and J.E.S. contributed equally to this work.

Correspondence should be addressed to Douglas A. Bayliss, Department of Pharmacology, University of Virginia Health System, P.O. Box 800735, Charlottesville, VA 22908-0735. E-mail: dab3y@virginia.edu.

Copyright (C) 2002 Society for Neuroscience $0270-6474 / 02 / 221256-10 \$ 15.00 / 0$ five members (Kim and Gnatenco, 2001; Patel and Honore, 2001) that can be further subdivided by sequence homology and functional properties. Included in one group are TASK-2 and TASK4/TALK-2 (Reyes et al., 1998; Gray et al., 2000; Decher et al., 2001; Girard et al., 2001), neither of which is strongly expressed in the brain (Girard et al., 2001; Talley et al., 2001). The other group includes TASK-1, TASK-3, and TASK-5. Of these, TASK-5 is distinct in that it has a very restricted CNS distribution (E. M. Talley and D. A. Bayliss, unpublished observations) and, to this point, has not been found to make a functional channel (Kim and Gnatenco, 2001; Vega-Saenz et al., 2001). In contrast, TASK-1 and TASK-3 are widely expressed throughout the brain, with overlapping distributions in many regions (Talley et al., 2000, 2001; Vega-Saenz et al., 2001). Moreover, they present a constellation of functional properties that is unique among all $\mathrm{K}^{+}$channels cloned to date. They generate essentially instantaneous, non-inactivating currents that have a weakly rectifying $I-V$ relationship in asymmetric $\mathrm{K}^{+}$that is predicted by constant field considerations [i.e., "open” or Goldman-HodgkinKatz (GHK) rectification]. Furthermore, they are regulated by extracellular $\mathrm{pH}$ in the physiological range, with $\mathrm{pK}$ for channel inhibition by protons of $\sim 7.4$ for TASK- 1 and $\sim 6.7$ for TASK-3, and they are activated by clinically appropriate concentrations of inhalation anesthetics (Lesage and Lazdunski, 2000; Goldstein et al., 2001; Patel and Honore, 2001).

Thus, TASK-1 and TASK-3 represent neuronal "leak" $\mathrm{K}^{+}$ channels that are sensitive to both extracellular $\mathrm{pH}$ and anesthetics. Understanding the neurobiological consequences that follow from the distinct modulatory potential intrinsic to TASK channels will depend, at least in part, on identifying the neurons that functionally express the channels. Here, we show that serotoner- 
gic dorsal and caudal raphe neurons express TASK-1 and TASK-3 transcripts and a $\mathrm{pH}$ - and anesthetic-sensitive $\mathrm{K}^{+}$conductance. In those cells, pH-dependent inhibition of TASK channels may contribute to ventilatory and arousal reflexes associated with extracellular acidosis; on the other hand, activation of raphe neuronal TASK channels by anesthetics could play a role in their immobilizing and sleep-inducing effects.

\section{MATERIALS AND METHODS}

\section{Histochemistry}

Preparation of histological specimens. For in situ hybridization using radiolabeled cRNA probes, adult rats (Wistar and Sprague Dawley; 200-350 gm) were anesthetized with ketamine and xylazine (200 and 14 $\mathrm{mg} / \mathrm{kg}$, i.m.) and decapitated, and brains were removed, blocked, and frozen on dry ice. Coronal sections $(10 \mu \mathrm{m})$ were cut through the brainstem in a cryostat, thaw-mounted onto charged slides (Superfrost Plus; Fisher Scientific, Houston, TX), and stored at $-80^{\circ} \mathrm{C}$. For nonisotopic hybridization and combined immunohistochemistry, four adult Sprague Dawley rats were anesthetized with pentobarbital $(60 \mathrm{mg} / \mathrm{kg}$, i.p.) and perfused transcardially with $200 \mathrm{ml}$ of PBS, $\mathrm{pH} 7.4$, followed by $4 \%$ phosphate-buffered paraformaldehyde (0.1 M PB; pH 7.4). The brainstem was removed, post-fixed overnight with the same fixative at $4^{\circ} \mathrm{C}$, and then sectioned in the coronal plane $(30 \mu \mathrm{m})$ on a vibratome. Sections were stored at $-20^{\circ} \mathrm{C}$ in a cryoprotectant solution [ $30 \%$ RNase free sucrose, $30 \%$ ethylene glycol, and $1 \%$ polyvinylpyrrolidone (PVP40) in $100 \mathrm{~mm}$ sodium phosphate buffer, $\mathrm{pH}$ 7.4] (Watson et al., 1986).

Preparation of hybridization probes. Hybridization probes were prepared as labeled sense and antisense RNA by in vitro transcription from cDNA templates by using SP6 or T7 RNA polymerase. The coding region of rat TASK-1 (obtained from A. T. Gray, University of California, San Francisco, CA; GenBank accession number AF031384) (Leonoudakis et al., 1998) was ligated into pcDNA3 (Invitrogen, San Diego, CA) using EcoRI and ApaI and linearized with HindIII for transcription using SP6 RNA polymerase to generate antisense probes; the corresponding sense probes were produced by linearizing with EcoRI and transcribing with T7 RNA polymerase. The coding region of rat TASK-3 was prepared by PCR using TASK-3 cDNA as a template (obtained from D. Kim, The Chicago Medical School, Chicago, IL; GenBank accession number AF192366) (Y. Kim et al., 2000) and ligated into pcDNA3 using BamHI and EcoRI. Antisense probes were generated by cutting the resulting construct with HindIII and transcribing with SP6; the cognate sense probes were made by linearizing with EcoRV and transcribing with T7. Transcription was performed in the presence of $\left[\alpha-{ }^{33} \mathrm{P}\right] \mathrm{UTP}$ for preparation of radioactive probes; radiolabeled RNA was separated from unincorporated nucleotides by ethanol precipitation. For nonradioactive in situ hybridization, the Riboprobe System kit (Promega, Madison, WI) was used to incorporate digoxigenin-11-UTP (Boehringer Mannheim, Indianapolis, IN) into in vitro transcripts. Probes were purified with ProbeQuant G-50 Micro Columns (Amersham Biosciences, Piscataway, $\mathrm{NJ}$ ), and the amount of digoxigenin-11-UTP incorporation was estimated from a dot blot with a dilution series of riboprobe and control RNA (standards from Boehringer Mannheim). Riboprobes were added directly to the prehybridization solution (see below) at concentrations that were similar in spot density to the control RNA $(\sim 20-100 \mathrm{ng} / \mu \mathrm{l})$.

Hybridization with $\left[{ }^{33} \mathrm{P}\right]$-labeled probes. Radioactive in situ hybridization was performed as described previously (Talley et al., 2001). Slidemounted sections were fixed briefly $(5 \mathrm{~min})$ in $4 \%$ paraformaldehyde, rinsed repeatedly in PBS, treated successively with glycine ( $0.2 \%$ in PBS) and acetic anhydride $(0.25 \%$ in $0.1 \mathrm{M}$ triethanolamine, $0.9 \%$ saline, $\mathrm{pH}$ 8 ), and dehydrated in a graded series of ethanols and chloroform. Hybridization was performed overnight at $60^{\circ} \mathrm{C}$ in a buffer of $50 \%$ formamide, $4 \times \mathrm{SSC}(1 \times \mathrm{SSC}: 150 \mathrm{~mm} \mathrm{NaCl}$ and $15 \mathrm{~mm}$ sodium citrate, $\mathrm{pH} 7), 1 \times$ Denhardt's solution $(0.02 \%$ each of Ficoll, polyvinylpyrrolidone, and bovine serum albumin), 10\% dextran sulfate, $100 \mathrm{~mm}$ DTT, $250 \mu \mathrm{g} / \mathrm{ml}$ yeast tRNA, and $0.5 \mathrm{mg} / \mathrm{ml} \mathrm{salmon}$ testes DNA. After hybridization, slides were washed through two changes of $4 \times$ SSC, treated with RNase A $(50 \mu \mathrm{g} / \mathrm{ml})$, washed again through two changes each of $2 \times$ SSC and $0.5 \times$ SSC, and finally subjected to a high-stringency wash of $0.1 \times$ SSC. Each of these washes lasted $20-30 \mathrm{~min}$. They were performed at $37^{\circ} \mathrm{C}$ and included $10 \mathrm{~mm}$ sodium thiosulphate, with the exception of the high-stringency wash, which was performed at $55^{\circ} \mathrm{C}$ without sodium thiosulphate.
Non-isotopic in situ hybridization combined with immunohistochemistry. Sections were removed from cryoprotectant solution, rinsed in sterile saline, and placed free-floating into prehybridization mixture at room temperature for $30 \mathrm{~min}$ and then at $37^{\circ} \mathrm{C}$ for $1 \mathrm{hr}$. The prehybridization mixture consisted of $0.6 \mathrm{M} \mathrm{NaCl}, 0.1 \mathrm{~m}$ Tris-Cl, $\mathrm{pH} 7.5,0.002 \mathrm{M}$ EDTA, $0.05 \% \mathrm{NaPPi}, 0.5 \mathrm{mg} / \mathrm{ml}$ yeast total RNA, $0.05 \mathrm{mg} / \mathrm{ml}$ yeast tRNA, $1 \times$ Denhardt's BSA, $50 \%$ formamide, $10 \%$ dextran sulfate, $0.05 \mathrm{mg} / \mathrm{ml}$ oligo-dA, $10 \mu \mathrm{M}$ of the four deoxynucleoside triphosphates, $0.5 \mathrm{mg} / \mathrm{ml}$ herring sperm DNA, and $10 \mathrm{~mm}$ DTT in an aqueous solution. Digoxigenin-labeled probes were added directly to the prehybridization solution, and sections were incubated at $55-60^{\circ} \mathrm{C}$ for $16-20 \mathrm{hr}$. Sections were rinsed through decreasing concentrations of salt solutions, treated with RNase $\mathrm{A}$ at $37^{\circ} \mathrm{C}$, and then subjected to a final high-stringency wash $\left(0.1 \times \mathrm{SSC}\right.$ at $55^{\circ} \mathrm{C}$ for $\left.60 \mathrm{~min}\right)$.

Sections were processed for immunochemical detection of digoxigenin with a sheep polyclonal anti-digoxigenin antibody conjugated to alkaline phosphatase (Boehringer Mannheim). After incubation in a blocking solution of $10 \%$ goat serum for $30 \mathrm{~min}$, sections were incubated in anti-digoxigenin antibody for $16-20 \mathrm{hr}$ at $4^{\circ} \mathrm{C}$. After rinsing, the alkaline phosphatase was reacted with nitroblue tetrazolium and 5-bromo-4chloro-3-indolyl-phosphate, 4-toluidine salt in a foil-wrapped container. The reaction was monitored periodically under a dissecting microscope and quenched with three $10 \mathrm{~min}$ rinses in $0.1 \mathrm{M}$ Tris and 1 mм EDTA, pH 8.5.

After in situ hybridization, sections were processed for immunohistochemical detection of tryptophan hydroxylase (TPH). At the conclusion of the quenching steps (see above), free-floating sections were rinsed in Tris-buffered saline, $\mathrm{pH} 7.4$, and incubated with primary antibody against TPH (1:1000, mouse monoclonal; Sigma, St. Louis, MO) for $16-20 \mathrm{hr}$ at $4^{\circ} \mathrm{C}$ in a solution containing $0.1 \%$ Triton $\mathrm{X}-100,10 \%$ goat serum, and 100 $\mathrm{mm}$ Tris-buffered saline. Sections were incubated with biotinylated goatanti-mouse IgG3 (1:200; Vector Laboratories, Burlingame, CA) and then with avidin-conjugated Cy3 (1:1000; Jackson ImmunoResearch, West Grove, PA), each for $45 \mathrm{~min}$ at room temperature with intervening rinses. Sections were mounted onto microscope slides, air dried, and coverslipped with VectaShield (Vector Laboratories).

Control experiments. The probes used for TASK channel in situ hybridization (Sirois et al., 2000; Talley et al., 2000, 2001) and the antibody used for detection of tryptophan hydroxylase (Bayliss et al., 1997) have been characterized extensively. Additional controls performed in the current context included the use of corresponding sense probes, which gave uniformly low levels of nonspecific (background) labeling (see Figs. 1,2). The patterns of labeling for TASK-1 and TASK-3 obtained with radioactive and non-isotopic cRNA probes were identical. In addition, the distribution of TPH immunoreactivity was exactly as expected for serotonergic neurons (i.e., strong labeling in midline raphe nuclei) (Jacobs and Azmitia, 1992), with no labeling evident in control tissue in which either the primary or secondary antibody was omitted (data not shown).

Brain mapping, quantification, and imaging. All slides from isotopic in situ hybridization experiments were exposed to film (Hyperfilm $\beta$-MAX; Amersham Biosciences) for the same length of time (5 d). The resulting autoradiograms were mounted on a light box and imaged using a video camera (CCD-72; Dage-MTI, Michigan City, IN). The same camera settings were used to generate images from each of the different probes. Sections from combined in situ hybridization and immunohistochemistry experiments were photographed with color slide film (Fuji Provia 1600; Fujifilm, Tokyo, Japan) or black and white film (Kodak TMAX 100; Eastman Kodak, Rochester, NY). A Nikon (Tokyo, Japan) film scanner at 3000 dpi resolution was used to digitize images for processing in Adobe Photoshop (Adobe Systems, San Jose, CA). Locations of TPHimmunoreactive (IR) neurons that contain TASK-1 or TASK-3 mRNA were mapped, and cell counts were obtained by using Neurolucida (MicroBrightField, Colchester, VT) and Canvas software (Deneba Software, Miami, FL) in sections containing raphe dorsalis (RDo), magnus $(\mathrm{RMg})$, obscurus (ROb), pallidus ( $\mathrm{RPa})$, and the parapyramidal region. Sections were located relative to bregma using landmarks from the atlas of Paxinos and Watson (1997).

\section{Electrophysiology}

General preparation. Whole-cell recordings were performed in vitro using brainstem slices, essentially as described previously (Sirois et al., 2000; Talley et al., 2000). Briefly, rats [Sprague Dawley, postnatal day 1 (P1) to P9 for caudal raphe and P15-P29 for dorsal raphe] were anesthetized either by chilling on ice $(<\mathrm{P} 5)$ or with ketamine-xylazine (as above), and 
the brainstem was removed after decapitation. Transverse slices (200 $\mu \mathrm{m})$ were cut with a microslicer (DSK-1000; Dosaka) in an ice-cold solution containing (in $\mathrm{mM}$ ): 260 sucrose, $3 \mathrm{KCl}, 5 \mathrm{MgCl}_{2}, 1 \mathrm{CaCl}_{2}, 1.25$ $\mathrm{NaH}_{2} \mathrm{PO}_{4}, 26 \mathrm{NaHCO}_{3}, 10$ glucose, and 1 kynurenic acid. Slices were incubated for $\sim 1 \mathrm{hr}$ at $37^{\circ} \mathrm{C}$ in a solution consisting of (in mM): $130 \mathrm{NaCl}$, $3 \mathrm{KCl}, 2 \mathrm{MgCl}_{2}, 2 \mathrm{CaCl}_{2}, 1.25 \mathrm{NaH}_{2} \mathrm{PO}_{4}, 26 \mathrm{NaHCO}_{3}$, and 10 glucose. Slices were maintained in this incubation solution at room temperature $\left(22-25^{\circ} \mathrm{C}\right)$ for periods up to $6 \mathrm{hr}$. Cutting and incubation solutions were bubbled continuously with $95 \% \mathrm{O}_{2}$ and $5 \% \mathrm{CO}_{2}$.

Recording. Slices were submerged in a chamber mounted on a fixedstage microscope (Axioskop FS; Zeiss, Thornwood, NY), perfused continuously $(\sim 2 \mathrm{ml} / \mathrm{min})$, and visualized using differential interference contrast optics. Dorsal and caudal raphe neurons were identified visually by their location ventral to the aqueduct or along the midline, respectively, and characterized electrophysiologically by their response to serotonin (5-hydroxytryptamine, 5-HT) (Jacobs and Azmitia, 1992; Penington et al., 1993; Bayliss et al., 1997). Electrical recordings were performed at room temperature in a bath solution composed of (in $\mathrm{mm}$ ): $130 \mathrm{NaCl}, 3 \mathrm{KCl}, 2 \mathrm{MgCl}_{2}, 2 \mathrm{CaCl}_{2}, 1.25 \mathrm{NaH}_{2} \mathrm{PO}_{4}, 10 \mathrm{HEPES}$, and 10 glucose, with $\mathrm{pH}$ adjusted using either $\mathrm{NaOH}$ or $\mathrm{HCl}$. For voltage-clamp recordings, bath solutions contained tetrodotoxin $(0.75-1 \mu \mathrm{M})$; for current-clamp recordings, slices were perfused in a bath solution containing bicuculline $(10 \mu \mathrm{M})$, strychnine $(30 \mu \mathrm{M})$, and CNQX $(10 \mu \mathrm{M})$

Patch electrodes were pulled from borosilicate glass capillaries (Warner Instruments, Hamden, CT) on a two-stage puller (Sutter Instruments, Novato, CA) to a DC resistance of $\sim 3-5 \mathrm{M} \Omega$ when filled with internal solution containing (in $\mathrm{mM}$ ): $120 \mathrm{KCH}_{3} \mathrm{SO}_{3}, 4 \mathrm{NaCl}_{2}, 1 \mathrm{MgCl}_{2}$ $0.5 \mathrm{CaCl}_{2}$, $10 \mathrm{HEPES}, 10$ EGTA, $3 \mathrm{Mg}$-ATP, and $0.3 \mathrm{GTP}-\mathrm{Tris}$, pH 7.2; electrode tips were coated with Sylgard 184 (Dow Corning, Midland, MI). 5-HT was applied at bath concentrations ranging from 2 to $100 \mu \mathrm{M}$. To augment 5-HT current amplitude in caudal raphe neurons, the concentration of $\mathrm{KCl}$ was increased to $6 \mathrm{~mm}$ during 5-HT application in some experiments (Penington et al., 1993). Osmolarity was maintained by reducing the concentration of $\mathrm{NaCl}$ correspondingly. All solutions were bubbled with a room air gas mixture $\left(21 \% \mathrm{O}_{2} /\right.$ balance $\left.\mathrm{N}_{2}\right)$ and perfused at $\sim 2 \mathrm{ml} / \mathrm{min}$; solutions containing halothane were equilibrated using a calibrated vaporizer (Ohmeda, Helsinki, Finland) and covered tightly with parafilm to prevent loss of anesthetic to the atmosphere. Aqueous concentrations of anesthetic solutions were determined by gas chromatographic analysis from samples collected at the point of presentation to the preparation (Sirois et al., 2000).

Data acquisition and analysis. Voltage commands were applied via an Axopatch 200B patch-clamp amplifier and digitized with a Digidata 1200 analog-to-digital converter (Axon Instruments, Union City, CA). Cells were held at $-60 \mathrm{mV}$, and membrane currents in response to a hyperpolarizing ramp $(-60$ to $-130 \mathrm{mV})$ were recorded at a constant interval $(0.1 \mathrm{~Hz})$. Current-voltage relationships were determined at steady state for various treatment protocols by hyperpolarizing the cell in $-10 \mathrm{mV}$ steps (to $-130 \mathrm{mV}$ ). Currents were filtered at $2 \mathrm{kHz}$ with a four-pole, low-pass Bessel filter. Series resistance was typically $<20 \mathrm{M} \Omega$ and was compensated by $65-70 \%$. A liquid junction potential of $-10 \mathrm{mV}$ was corrected offline. Data analysis was performed using the pClamp suite of programs (Axon Instruments). Statistical analysis of data were performed using Student's $t$ tests; significance was accepted if $p<0.05$.

\section{RESULTS}

\section{Expression of TASK channel transcripts in midline brainstem neurons of rat}

We determined sites of TASK channel expression in midline structures of the rat brainstem using in situ hybridization with $\left[{ }^{33} \mathrm{P}\right]$-labeled antisense RNA probes. Images from these experiments are shown in Figure 1, together with control data from sagittal sections of rat brain hybridized with sense and antisense probes (Fig. $1 E-H)$, which illustrate the low level of background labeling obtained in these experiments. In film autoradiographs of coronal sections through the RDo, TASK-1 mRNA was detected at moderate levels (Fig. $1 A$ ), whereas TASK-3 expression was found at high levels (Fig. $1 B$ ). In more caudal brainstem sections, film autoradiographs reveal expression of TASK-1 (Fig. $1 C$ ) and TASK-3 (Fig. 1D) along the midline, in structures corresponding to ROb and RPa. TASK-1 was expressed at much

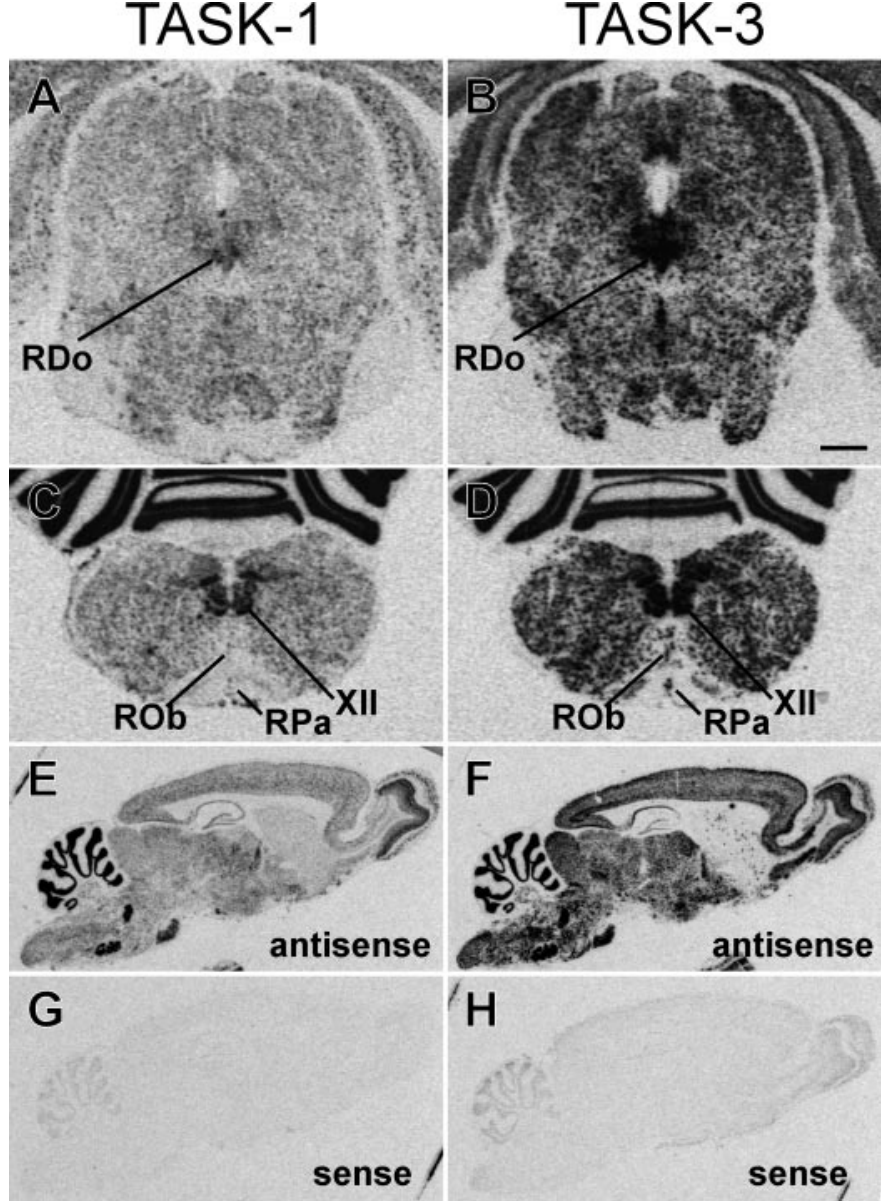

Figure 1. Expression of TASK channel transcripts in midline raphe cell groups. In situ hybridization was performed in parallel on sections of rat brainstem using $\left[{ }^{33} \mathrm{P}\right]$-labeled RNA probes complementary to TASK-1 and TASK-3. Film autoradiographs from coronal sections of midbrain show moderate levels of TASK-1 expression $(A)$ and high levels of TASK-3 expression $(B)$ in the RDo. In transverse sections from the medulla oblongata, film autoradiographs depict expression of TASK-1 $(C)$ and TASK-3 $(D)$ in the caudal raphe cell groups ROb and RPa. Strong labeling in the hypoglossal motor nuclei $(X I I)$ is also apparent TASK-1 is expressed at lower levels in raphe cell groups than in motoneurons, whereas levels of TASK-3 are more comparable in those two cell types. It also appeared that TASK-1 was expressed at lower levels than TASK-3, although comparisons between probes should be made with caution. Autoradiographs of sagittal rat brain sections from control experiments performed with antisense $(E, F)$ and sense $(G, H)$ probes to TASK-1 $(E, G)$ and TASK-3 $(F, H)$ illustrate differential but overlapping brain distribution of TASK channel transcripts and low levels of background labeling. Scale bar: $A-D, 1 \mathrm{~mm} ; E-H, 2.5 \mathrm{~mm}$.

lower levels in raphe neurons than in the hypoglossal motoneurons that are apparent in the same sections, whereas expression of TASK-3 was more similar in the two cell groups, although at slightly higher levels in motoneurons. In addition, if one assumes similar hybridization efficiencies for the two probes, it appeared that TASK-3 was expressed at higher levels than TASK-1 in both raphe neurons and motoneurons.

\section{Expression of TASK channel transcripts in brainstem serotonergic neurons}

The major serotonergic cell groups in the brain are coextensive with midline brainstem raphe nuclei, although a substantial proportion of raphe cells are not serotonergic (Jacobs and Azmitia, 1992). To determine whether TASK channel transcripts are ex- 


\section{TASK-1}
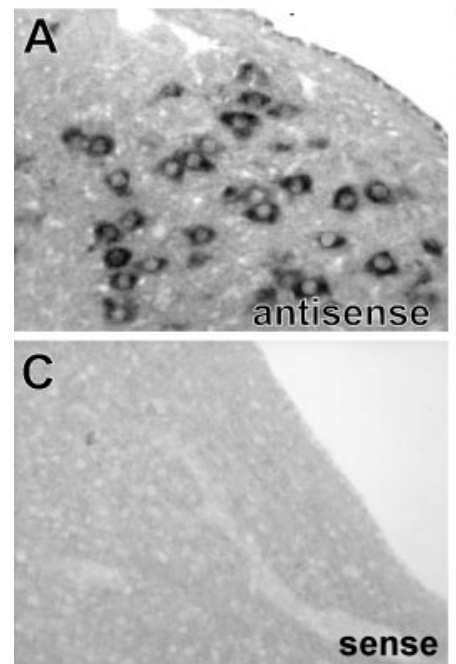

TASK-3

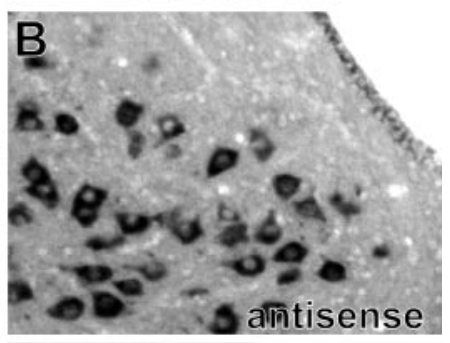

D

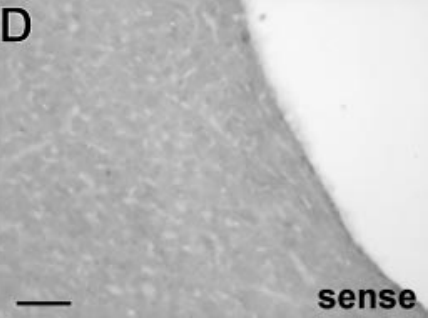

Figure 2. Specificity of TASK-3 and TASK-1 labeling using nonradioactive cRNA probes. In situ hybridization with digoxigenin-labeled sense and antisense RNA probes for TASK-1 and TASK-3. Note that high levels of TASK-1 $(A)$ and TASK-3 $(B)$ expression were detected in hypoglossal motoneurons using antisense probes; as expected, there was no labeling in motoneurons in adjacent sections incubated with the corresponding sense probes $(C, D)$. Scale bar, $50 \mu \mathrm{m}$.

pressed in serotonergic raphe neurons, we used nonradioactive in situ hybridization with digoxigenin-labeled RNA probes for TASK channels combined with immunohistochemical localization of tryptophan hydroxylase, the rate-limiting enzyme in serotonin biosynthesis. In control experiments, prominent alkaline phosphatase reaction product was observed in motoneurons from tissue incubated with digoxigenin-labeled TASK channel antisense riboprobes but completely absent in control tissue incubated with sense probes (Fig. 2). Moreover, the distribution of TASK-expressing brainstem neurons obtained using nonradioactive probes conformed to previous in situ hybridization examinations (Talley et al., 2000, 2001), again with stronger labeling for TASK-3 than for TASK-1. In addition, the localization of TPH immunoreactivity was exactly as expected for serotonergic neurons (i.e., strong labeling in midline raphe nuclei) (Jacobs and Azmitia, 1992).

Combined labeling for TASK channel transcripts and TPH in the midbrain dorsal raphe nucleus is shown in Figure 3. Lowpower photomicrographs reveal labeling in RDo for TASK-1 (Fig. $3 A$ ) and TASK-3 mRNA (Fig. $3 E$ ), with high correspondence to the region of TPH immunoreactivity (Fig. $3 B, F$ ). At higher magnification, numerous individual cells were evident that contain TASK channel transcripts (Fig. 3C,G) and TPH immunoreactivity (Fig. $3 D, H$ ), and it was clear that, in most cases, TASK mRNA was coexpressed in the TPH-IR neurons (see arrows), indicating that serotonergic RDo neurons express TASK channel transcripts. Labeling for TASK was seen in a few nonserotonergic neurons (arrowheads), but TPH-IR cells that did not contain TASK mRNA were encountered only infrequently. Colocalization of TASK channel mRNA in serotonergic neurons was not limited to the dorsal raphe but was also evident along the midline of the caudal brainstem within the ROb and RPa (Fig. 4). High-power photomicrographs show expression of TASK-1 in TPH-IR cells of ROb (Fig. 4A,B) and TASK-3 in TPH-IR cells of $\mathrm{RPa}$ (Fig. $4 C, D$ ); it is again clear that hybridization signal for

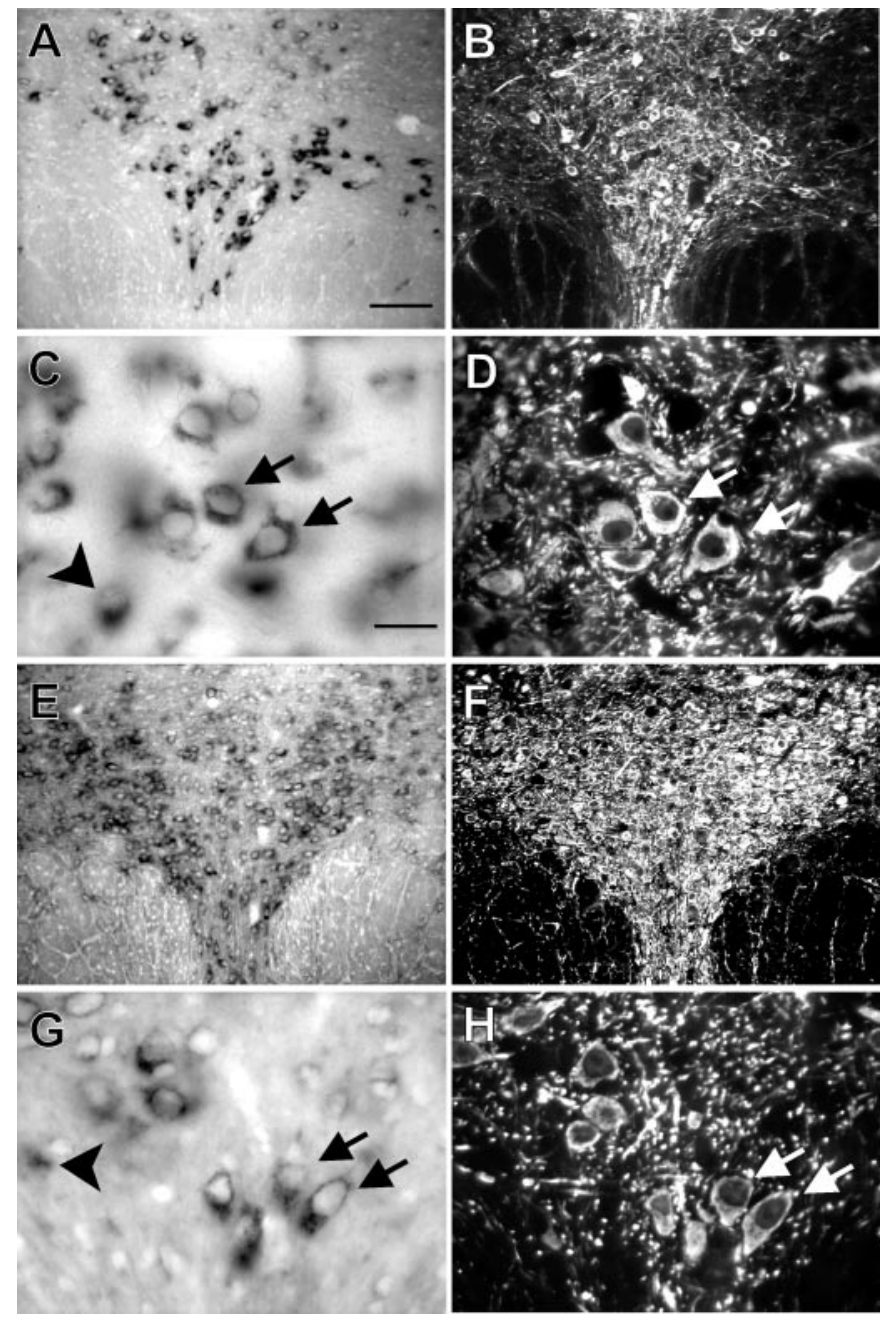

Figure 3. TASK-1 and TASK-3 transcripts are expressed in TPH-IR neurons of the dorsal raphe. In situ hybridization with digoxigenin-labeled RNA probes complementary to TASK- 1 and TASK- 3 was combined with immunohistochemistry for TPH on coronal sections of rat midbrain at the level of RDo. Low-powered bright-field images show labeling for TASK-1 $(A)$ and TASK-3 $(E)$; fluorescence photomicrographs of the same sections reveal immunostaining for TPH $(B, F)$. Note the strong correspondence in localization of TASK-expressing and TPH-immunoreactive (i.e., serotonergic) cells. High-magnification bright-field images show individual TASK-1-labeled neurons $(C)$ and TASK-3-labeled neurons $(G)$; immunofluorescence photomicrographs identify TPH-IR neurons in the same sections $(D, H)$. It is clear that most serotonergic neurons express TASK channels (arrows); some TASK-expressing neurons that are not noticeably TPH-IR were also apparent (see arrowheads in $C$ and $G$ ). Scale bars: $A, 100 \mu \mathrm{m} ; C, 25 \mu \mathrm{m}$. Sections in $A-D$ were taken from a slightly different rostrocaudal level than those in $E-H$.

TASK mRNA was found in many TPH-IR cells (arrows) and in some apparently nonserotonergic cells (arrowheads).

To quantify these results, we mapped the distribution of TASK channel transcripts within serotonergic raphe neurons. Sections were examined at levels that contain $\mathrm{RDo}, \mathrm{RMg}, \mathrm{ROb}, \mathrm{RPa}$, and the parapyramidal areas; these maps were used to determine the percentage of TPH-IR neurons in which TASK-1 or TASK-3 transcripts were colocalized (Table 1). Combining data obtained from all raphe nuclei, cell counts revealed that the majority of the TPH-IR cells contained TASK-1 $(73 \%)$ or TASK-3 (81\%) mRNA. A similar percentage of TPH-IR neurons within the RDo contained transcripts for TASK-1 or TASK-3. In the me- 

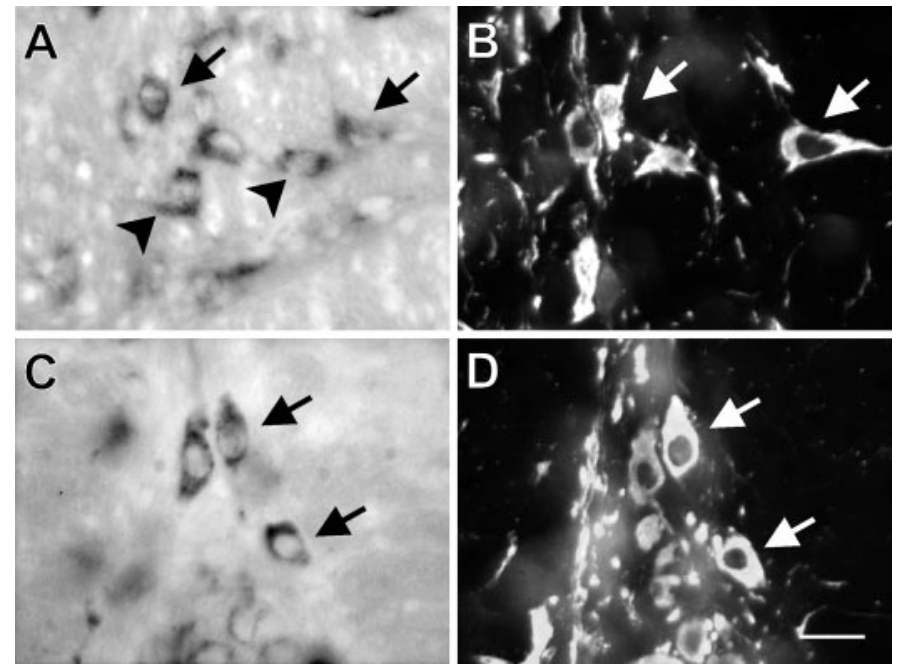

Figure 4. TASK-1 and TASK-3 transcripts are colocalized in serotonergic neurons of the caudal raphe. In situ hybridization with digoxigeninlabeled RNA probes complementary to TASK-1 and TASK-3 was combined with immunohistochemistry for TPH on coronal sections of rat brainstem. $A, C$, TASK-1-expressing neurons of ROb and TASK-3expressing neurons of RPa are shown in bright-field photomicrographs. $B$, $D$, Immunofluorescence photomicrographs of the corresponding sections shows the location of TPH-IR neurons. Many serotonergic neurons contain TASK channel transcripts (arrows); TASK channel expression was also observed in TPH-IR negative neurons (arrowheads). Scale bar, $25 \mu \mathrm{m}$.

dulla, it appeared that a higher percentage of TPH-IR cells contained TASK-3 than TASK-1, although this may partly reflect difficulties with detection of TASK-1 as a result of its apparently lower expression.

\section{Dorsal raphe neurons express a $\mathrm{pH}$ - and halothane-sensitive $\mathrm{K}^{+}$conductance with properties of TASK channels}

TASK-1 and TASK-3 channels generate instantaneous, openrectifier $\mathrm{K}^{+}$currents that are sensitive to extracellular $\mathrm{pH}$ and to volatile anesthetics (Lesage and Lazdunski, 2000; Goldstein et al., 2001; Patel and Honore, 2001). Given that TASK-1 and TASK-3 transcripts are expressed in serotonergic raphe neurons, we tested whether those cells exhibit $\mathrm{pH}$ - and anesthetic-sensitive currents with the properties expected of TASK channels. To this end, whole-cell voltage-clamp recordings were obtained in brainstem slices from neurons in RDo (Figs. 5, 6). All cells included in this study generated an inwardly rectifying $\mathrm{K}^{+}$current in response to bath application of 5-HT, a response characteristic of serotonergic raphe neurons (Jacobs and Azmitia, 1992; Penington et al., 1993; Bayliss et al., 1997). In the representative cell of Figure $5 A$, this effect is evident as a 5-HT-induced outward shift in current at the holding potential of $-60 \mathrm{mV}$.

In these 5-HT-responsive, and thus presumably serotonergic RDo cells, we characterized currents that were sensitive to bath acidification and to halothane, following the protocol illustrated in Figure $5 A$. Bath acidification (from $\mathrm{pH} 7.3$ to $\mathrm{pH} 6.0$ ) produced a small but reproducible inward shift in holding current. Subsequent application of halothane $(1.25 \mathrm{~mm})$ at $\mathrm{pH} 7.3$ evoked an outward current, and, in the continued presence of halothane, bath acidification again induced an inward current shift, but that current was now enhanced in amplitude. Every RDo neuron tested with this protocol showed an enhanced $\mathrm{pH}$-sensitive cur- rent in the presence of halothane $(n=14)$. Averaged data from these cells revealed that the inward shift in holding current obtained during bath acidification was $-9.9 \pm 1.3 \mathrm{pA}$ under control conditions and $-25.6 \pm 2.6 \mathrm{pA}$ in the presence of halothane $(p<0.001)$; the outward current induced by halothane itself was $27.7 \pm 3.8 \mathrm{pA}$.

Current responses to hyperpolarizing voltage steps obtained under these conditions (at points corresponding to those indicated by lowercase letters in Fig. $5 A$ ) are depicted in Figure $5 B$. Note that currents were fully activated within the time needed to charge the membrane and note also the absence of any significant time-dependent current relaxation in these records. Subtracting control currents from those obtained in $\mathrm{pH} 6.0$ yielded the $\mathrm{pH}$ sensitive current; those subtracted currents were obtained in a group of RDo neurons to determine the averaged $I-V$ relationship of the $\mathrm{pH}$-sensitive current (Fig. 5C, diamonds). This averaged $I-V$ relationship was associated with a negative slope, consistent with inhibition of a $\mathrm{K}^{+}$conductance. However, it did not reverse over the voltage range tested, suggesting that additional conductances likely contribute to $\mathrm{pH}$-sensitive currents in RDo neurons. A similar subtraction procedure was used to determine the $I-V$ relationship of the $\mathrm{pH}$-sensitive current obtained in the presence of halothane (Fig. 5C, squares); under these conditions, the $\mathrm{pH}$-sensitive current was associated with a more prominent decrease in conductance. As shown in Figure 5D, subtraction of $\mathrm{pH}$-sensitive currents in the presence of halothane from those in the absence of halothane yielded the component of $\mathrm{pH}$-sensitive current that was enhanced by halothane. The $I-V$ relationship of this subtracted current reversed near $E_{\mathrm{K}}$ and was well fitted by the GHK constant field equation, indicating that like TASK currents, the joint halothane- and $\mathrm{pH}$-sensitive current in $\mathrm{RDo}$ displayed properties expected of an open rectifier $\mathrm{K}^{+}$conductance.

\section{TASK-1 and TASK-3 contribute to the dorsal raphe $\mathrm{pH}-$ and halothane-sensitive $\mathrm{K}^{+}$current}

We found expression of both TASK-1 and TASK-3 channel mRNA in serotonergic raphe neurons, with apparently higher expression of TASK-3. Although these TASK channels are each modulated by extracellular $\mathrm{pH}$, they exhibit a different range of sensitivity; TASK-1 is activated strongly by bath alkalization from pH 7.3 (Duprat et al., 1997; Leonoudakis et al., 1998; Y. Kim et al., 1999; Lopes et al., 2000; Talley et al., 2000), whereas TASK-3 is nearly fully activated at $\mathrm{pH} 7.3$, and additional alkalization has little effect on TASK-3 currents (Y. Kim et al., 2000; Rajan et al., 2000; Meadows and Randall, 2001). As shown in Figure $6 A$, and consistent with a contribution of TASK- 1 to the $\mathrm{pH}$ - and anesthetic-sensitive current in RDo neurons, we found an outward shift in holding current when the $\mathrm{pH}$ of the bath solution was increased from 7.3 to 8.4 , both under control conditions $(6.4 \pm 3.3 \mathrm{pA})$ and in the presence of halothane $(16.2 \pm 5.8$ $\mathrm{pA} ; n=11)$. These effects were associated with an increase in conductance, and $I-V$ relationships of the current induced by bath alkalization in the presence of halothane displayed properties consistent with activation of an open-rectifier $\mathrm{K}^{+}$conductance (Fig. 6B).

To characterize further the $\mathrm{pH}$ sensitivity of the raphe neuronal current, we varied extracellular $\mathrm{pH}$ in the continued presence of halothane (i.e., under conditions that maximize the contribution of TASK-like currents to the $\mathrm{pH}$ response). As shown in Figure $6 C$, currents were measured in bath solutions titrated to four different $\mathrm{pH}$ values in the presence of halothane. Currents 


\begin{tabular}{lll}
\hline Table 1. Colocalization of TASK-1 or TASK-3 mRNA within TPH-IR neurons & $\begin{array}{l}\text { Percentage of TPH-IR neurons } \\
\text { that express TASK-3 }\end{array}$ \\
Brain region & $\begin{array}{l}\text { Percentage of TPH-IR neurons } \\
\text { that express TASK-1 }\end{array}$ & $79.2 \pm 0.6(n=11)$ \\
\hline Parapyramidal region & $66.0 \pm 0.5(n=12)$ & $85.3 \pm 1.0(n=11)$ \\
Raphe pallidus & $66.7 \pm 0.6(n=12)$ & $95.6 \pm 2.0(n=7)$ \\
Raphe obscurus & $70.1 \pm 0.6(n=8)$ & $72.6 \pm 0.8(n=4)$ \\
Raphe magnus & $70.6 \pm 0.9(n=4)$ & $87.4 \pm 1.1(n=4)$ \\
Raphe dorsalis & $85.5 \pm 1.1(n=4)$ & \\
\hline
\end{tabular}

$n$, Number of sections examined.

A

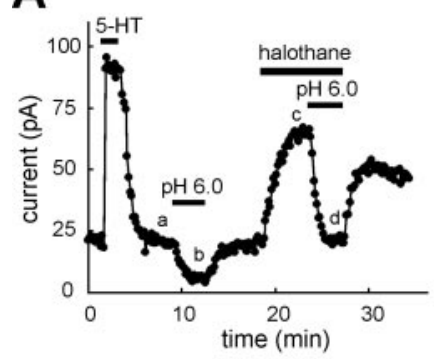

B

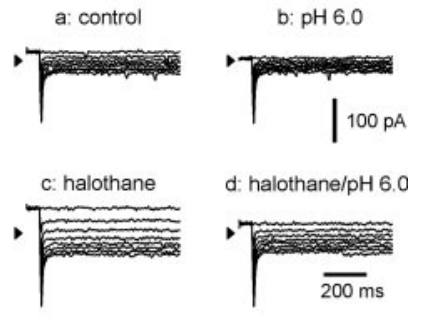

C

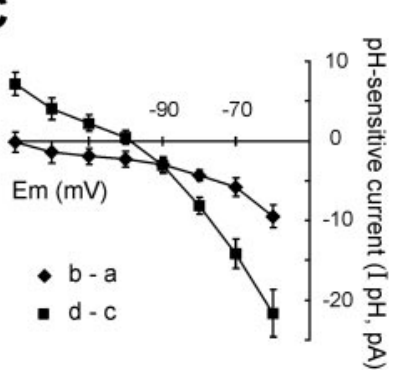

D

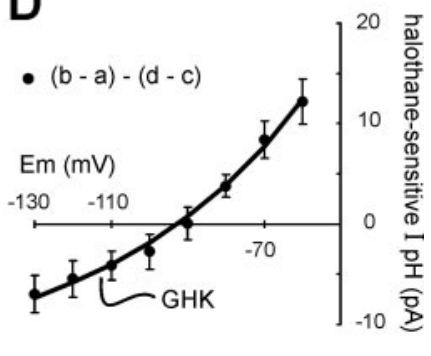

Figure 5. Dorsal raphe neurons express a $\mathrm{pH}$ - and halothane-sensitive $\mathrm{K}^{+}$conductance with properties of TASK channels. Dorsal raphe neurons were recorded under whole-cell voltage clamp in slices of rat midbrain. $A$, As expected for serotonergic dorsal raphe neurons, 5-HT (100 $\mu \mathrm{M})$ evoked an outward shift in membrane current at holding potential of $-60 \mathrm{mV}$. Extracellular acidification (from $\mathrm{pH} 7.3$ to $\mathrm{pH}$ 6.0) evoked an inward shift in holding current. After wash into control pH 7.3 solution, halothane $(1.25 \mathrm{mM})$ evoked an outward shift in current, and, in the presence of halothane, the current shift induced by reacidifying the bath solution was enhanced in amplitude. $B$, Examples of current responses to incrementing voltage steps $(\Delta-10 \mathrm{mV})$ from $-60 \mathrm{mV}$ that were used to construct $I-V$ relationships (taken at times corresponding to those indicated in $A$ ); note that currents were essentially completely activated before the end of the capacitive transient (i.e., they were instantaneous) and were non-inactivating. $C$, Averaged $I-V$ relationships of $\mathrm{pH}$-sensitive currents (diamonds) were derived by subtracting currents recorded in the acidified bath $(b)$ from those obtained under control conditions $(a)$; the $\mathrm{pH}$-sensitive current in the presence of halothane (squares) was likewise derived by subtracting currents recorded before $(c)$ and after $(d)$ bath acidification during continued exposure to halothane ( \pm SEM; $n=14)$. $D$, Subtracting $\mathrm{pH}$-sensitive currents obtained in the presence of halothane from those obtained under control conditions yielded the averaged $I-V$ relationship of the joint halothane- and $\mathrm{pH}$-sensitive component of dorsal raphe current $( \pm$ SEM; $n=14)$. Those $I-V$ data were well fitted to the GHK equation, consistent with involvement of an open-rectifier TASKlike current.

were normalized, and a $\mathrm{pH}$ curve was generated by a logistic fit to the data (Fig. $6 D$ ). The calculated $\mathrm{pK}$ for RDo neurons was $\sim 7.0$, intermediate between that reported for rTASK-1 (pK 7.4) (Talley et al., 2000) and rTASK-3 (pK 6.7) (Y. Kim et al., 2000), suggesting that both channels contribute to the $\mathrm{pH}-$ and anesthetic-sensitive current in RDo neurons.
A

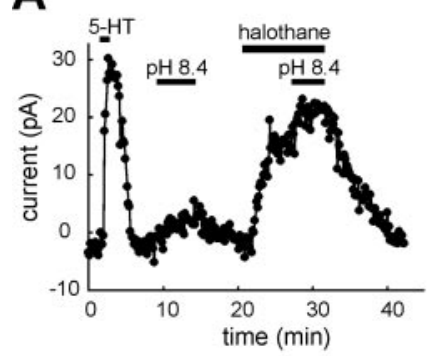

B

C

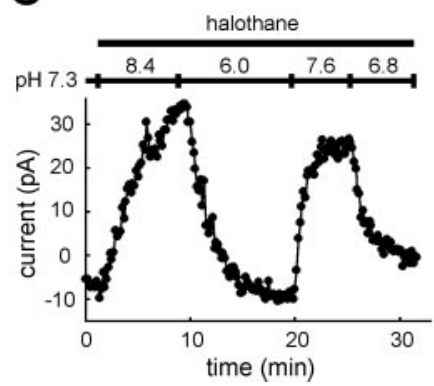

D

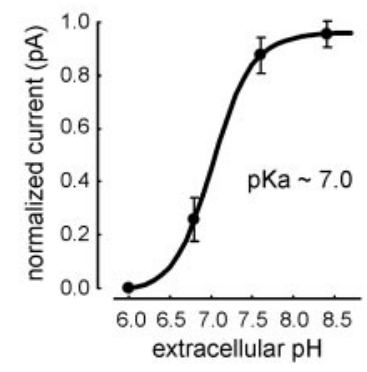

Figure 6. The $\mathrm{pH}$ - and anesthetic-sensitive current in $\mathrm{RDo}$ has a $\mathrm{pH}$ sensitivity intermediate between TASK-1 and TASK-3. $A$, Voltage-clamp recording in a serotonergic dorsal raphe neuron. 5-HT $(100 \mu \mathrm{M})$ induced an outward shift in membrane current at $-60 \mathrm{mV}$ that is characteristic of serotonergic RDo neurons. Bath alkalization (from $\mathrm{pH} 7.3$ to $\mathrm{pH} 8.4$ ) evoked an outward current under control conditions and in the presence of halothane $(1.25 \mathrm{~mm}) . B$, Averaged data depicting the $I-V$ relationship of the current evoked by alkalized solution in halothane; these data were well fitted with the GHK constant field equation ( \pm SEM; $n=11$ ). $C$, To determine the $\mathrm{pH}$ sensitivity of currents in RDo neurons, the extracellular $\mathrm{pH}$ was varied between $\mathrm{pH} 6.0$ and $\mathrm{pH} 8.4$ in the continued presence of halothane (to enhance the amplitude of $\mathrm{pH}$-sensitive currents). $D$, For each cell, currents measured under these $\mathrm{pH}$ conditions were normalized to the maximum and minimum current, and those normalized data were fitted to a logistic equation that predicted a $\mathrm{pK}$ of $\sim 7.0$ for the $\mathrm{pH}-$ and halothane-sensitive dorsal raphe current. This value is intermediate between those measured for cloned rTASK-1 and rTASK-3 ( $~ 7.4$ and 6.7, respectively).

\section{The $\mathrm{pH}$ - and anesthetic-sensitive current in caudal raphe neurons has properties of an open-rectifier $\mathrm{K}^{+}$conductance}

In addition to TASK-expressing cells in the RDo, we found that a high percentage of medullary serotonergic neurons express TASK channel transcripts. Accumulating evidence indicates that firing activity of serotonergic caudal raphe neurons is modulated by physiological changes in $\mathrm{pH}$ (Richerson, 1995; Wang and Richerson, 2000; Wang et al., 2001). Therefore, we tested whether TASK-like currents might also contribute to the $\mathrm{pH}$ sensitivity of medullary raphe neurons.

We characterized $\mathrm{pH}$ - and anesthetic-sensitive currents in cau- 
A

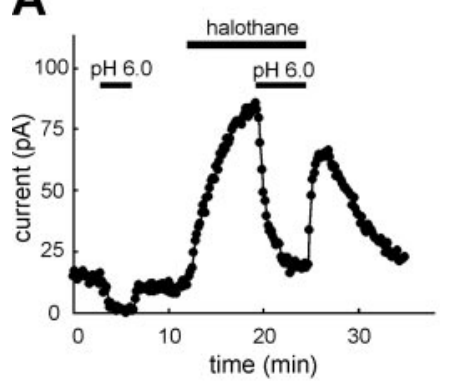

B

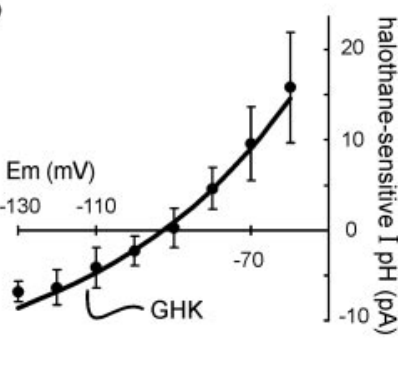

C

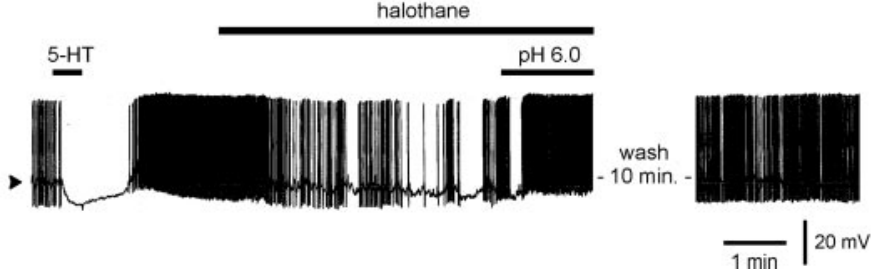

Figure 7. Caudal raphe neurons also express a $\mathrm{pH}-$ and halothanesensitive open-rectifier $\mathrm{K}^{+}$current. $A$, Voltage-clamp recording of membrane current in a representative caudal raphe cell held at $-60 \mathrm{mV}$. Extracellular acidification evoked an inward shift in holding current that reversed when the cell was returned to the control bath solution. Addition of halothane $(1.25 \mathrm{~mm})$ to the bath then induced an outward current, and, in the continued presence of halothane, the inward shift in current associated with bath acidification was increased in amplitude. This cell responded to a subsequent bath application of 5-HT $(2 \mu \mathrm{M})$ with an outward current (data not shown) characteristic of serotonergic caudal raphe neurons. $B$, The averaged $I-V$ relationship of the $\mathrm{pH}-$ and halothane-sensitive current ( \pm SEM; $n=7$ ) was determined from cells tested with this same protocol using the subtraction procedure described above (see Fig. 5); these data were well fitted with the GHK equation, indicating that the $\mathrm{pH}$ - and halothane-sensitive current in caudal raphe neurons is an open rectifier, as expected for TASK channel currents. $C$, Current-clamp recording of membrane potential in a spontaneously firing caudal raphe neuron. As expected for serotonergic raphe neurons, the cell hyperpolarized by $\sim 10 \mathrm{mV}$ and ceased its spike discharge when exposed to 5-HT $(2 \mu \mathrm{M})$. After recovery from 5-HT, a clinically relevant concentration of halothane $(0.35 \mathrm{~mm})$ reduced firing in this cell; the effect on firing was reversed by bath acidification (to $\mathrm{pH} 6.0$ ) and recovered to near control levels after wash of halothane in a neutral bath solution ( $\mathrm{pH} 7.3$ ). The current-clamp recording was obtained in a bath solution containing bicuculline $(10 \mu \mathrm{M})$, strychnine $(10 \mu \mathrm{M})$, and CNQX $(10 \mu \mathrm{M})$. Arrowhead indicates $-60 \mathrm{mV}$; action potentials were truncated by the chart recorder.

dal raphe neurons using the same protocol used in RDo neurons. Again, our analysis was limited to those cells that responded to 5-HT with an increase in an inwardly rectifying $\mathrm{K}^{+}$current (data not shown) typical of serotonergic neurons (Bayliss et al., 1997). As exemplified in the records of Figure 7, the response of caudal raphe neurons to bath acidification and halothane was essentially identical to that described above for RDo (compare with Fig. 5); acidification produced an inward shift in holding current that was enhanced in the presence of halothane. All caudal raphe neurons tested with this protocol displayed an enhanced pH-sensitive current in the presence of halothane $(n=7)$. The current induced by bath acidification averaged $-8.5 \pm 2.0 \mathrm{pA}$ under control conditions and $-26.0 \pm 8.3 \mathrm{pA}$ in the presence of halothane $(p<$ $0.05)$, which itself induced a $32.5 \pm 9.2 \mathrm{pA}$ current in those same cells. As with RDo neurons, the $I-V$ relationships of $\mathrm{pH}-$ and halothane-sensitive current in caudal raphe neurons displayed properties consistent with involvement of an openly rectifying $\mathrm{K}^{+}$channel, as illustrated in Figure $7 B$. This suggests that TASK channels contribute also to the $\mathrm{pH}$ sensitivity of serotonergic caudal raphe neurons.
Halothane depresses raphe neuronal firing at clinically relevant concentrations

Our data indicate that the halothane-sensitive current in raphe neurons is sensitive to $\mathrm{pH}$ in a physiological range, with a $\mathrm{pK}$ intermediate between that of cloned TASK-1 and TASK-3 channels (Fig. 6), and previous reports indicate that spike discharge in caudal raphe neurons is steeply sensitive to physiological changes in pH (Richerson, 1995; Wang and Richerson, 2000; Wang et al., 2001). It is also clear that cloned TASK channels are activated by anesthetics in a clinically relevant concentration range (Patel et al., 1999; Meadows and Randall, 2001). Therefore, we tested whether the firing behavior of raphe neurons is modulated by halothane at concentrations appropriate for clinical anesthesia. As depicted in the records from a 5-HT-responsive caudal raphe neuron in Figure $7 C$, a clinically relevant concentration of halothane $(0.35 \mathrm{~mm})$ caused membrane hyperpolarization and a marked decrease in spontaneous firing. This effect was reversed by acidifying the bath despite the continued presence of halothane, as expected if it were mediated by TASK channels (Sirois et al., 2000). Halothane depressed spike discharge in all dorsal raphe neurons $(n=4)$ and in all but one caudal raphe neuron ( $n=10$ of 11$)$ tested at this concentration; on average, halothane decreased firing from $0.5 \pm 0.1$ to $0.1 \pm 0.1 \mathrm{~Hz}$ in dorsal raphe neurons $(p<0.005)$ and from $0.5 \pm 0.1$ to $0.3 \pm 0.1 \mathrm{~Hz}$ in caudal raphe neurons $(p<0.001)$.

\section{DISCUSSION}

We combined molecular neuroanatomy and cellular electrophysiology to provide evidence that the $\mathrm{pH}$ - and anesthetic-sensitive two-pore-domain $\mathrm{K}^{+}$channels, TASK-1 and TASK-3, are functionally expressed in serotonergic raphe neurons. Thus, by using in situ hybridization, we showed that TASK-1 and TASK-3 transcripts are expressed in brainstem raphe nuclei; within the raphe, immunohistochemical detection of tryptophan hydroxylase in TASK-expressing neurons demonstrated that both TASK-1 and TASK-3 are localized within the majority of serotonergic dorsal and caudal raphe neurons $(\sim 70-90 \%)$. Whole-cell recordings of 5-HT-responsive, presumably serotonergic, raphe neurons revealed that those cells express a $\mathrm{K}^{+}$conductance with properties diagnostic of TASK channels and distinct from all other channels cloned to date (i.e., they display an instantaneous open-rectifier $\mathrm{K}^{+}$current that is jointly sensitive to $\mathrm{pH}$ and inhalational anesthetics). Because both TASK-1 and TASK-3 transcripts were found in a high percentage of serotonergic raphe neurons, it is certain that they must be coexpressed in many of those cells. Accordingly, the $\mathrm{pH}$ sensitivity of the raphe neuronal TASK-like current $(\mathrm{pK} \sim 7.0)$ was intermediate between TASK-1 and TASK-3, consistent with contributions from both channels. These data suggest that modulation of TASK channels by extracellular protons and by anesthetics may contribute to neurophysiological mechanisms related to brain $\mathrm{pH}$ homeostasis and to clinical effects of inhalational anesthetics mediated by serotonergic raphe neurons.

\section{Methodological considerations}

Throughout most of these studies, we used $\mathrm{pH}$ conditions and anesthetic concentrations designed to maximize current amplitudes, and this may have activated additional processes that would not be obtained under physiologically or clinically appropriate conditions. However, it is well known that recombinant TASK channels are sharply sensitive to extracellular $\mathrm{pH}$ in the physiological range (Duprat et al., 1997; D. Kim et al., 1998; Leo- 
noudakis et al., 1998; Y. Kim et al., 1999, 2000; Lopes et al., 2000; Rajan et al., 2000; Talley et al., 2000; Meadows and Randall, 2001), and, with a $\mathrm{pK} \sim 7.0$ as we described, the $\mathrm{pH}$-sensitivity of the raphe neuronal TASK-like current indicates that it will be regulated by physiological changes in $\mathrm{pH}$. Likewise, it is clear that TASK channels are sensitive to anesthetics at clinically relevant concentrations (Patel et al., 1999; Meadows and Randall, 2001), and, accordingly, we found that halothane induced a $\mathrm{pH}$-sensitive decrease in raphe neuronal excitability at clinically appropriate concentrations. Although there is no evidence to date for the existence of native heteromeric TASK-1/TASK-3 channels, such as one might expect from their coexpression in serotonergic raphe neurons, we found that concatenated TASK-1/TASK-3 constructs express channels that also respond to extracellular $\mathrm{pH}$ and inhalation anesthetics in a physiologically and clinically appropriate range (Talley and Bayliss, unpublished observations).

The protocol we used to isolate a time-independent, openrectifier TASK-like current took advantage of the joint $\mathrm{pH}$ and anesthetic sensitivity of TASK channels. Thus, a contribution of TASK channels to raphe neuronal $\mathrm{pH}$-sensitive currents was readily revealed in the presence of halothane, under conditions when TASK currents were enhanced. In addition, although $I-V$ relationships of the baseline $\mathrm{pH}$ current in the absence of anesthetic implied involvement of multiple conductances, the overall decrease in conductance associated with that baseline acidsensitive current suggests a contribution from inhibition of a background $\mathrm{K}^{+}$conductance. Moreover, because TASK channels are known to impart a constitutive background $\mathrm{K}^{+}$conductance in all contexts examined to date (Duprat et al., 1997; D. Kim et al., 1998; Leonoudakis et al., 1998; Y. Kim et al., 1999, 2000; Lopes et al., 2000; Rajan et al., 2000; Talley et al., 2000; Meadows and Randall, 2001), it seems likely that they would also represent a component of the background $\mathrm{pH}$-sensitive current in raphe neurons. Therefore, our data support the conclusion that upmodulation and downmodulation of background TASK channel activity by physiological changes in extracellular $\mathrm{pH}$ and by clinically relevant anesthetic concentrations will contribute to dynamic regulation of serotonergic neuronal excitability.

\section{Physiological relevance of a $\mathrm{pH}-$ sensitive background $\mathrm{K}^{+}$current in serotonergic raphe neurons}

The physiological relevance of the intrinsic $\mathrm{pH}$ sensitivity of serotonergic raphe neurons, including that conferred by TASK channels, remains to be established. In this respect, two important neural reflexes are evoked when brain $\mathrm{pH}$ is decreased by hypercapnia: (1) enhanced respiratory output, which serves as a homeostatic mechanism to correct changes in brain $\mathrm{pH}$ (Nattie, 1999); and (2) behavioral arousal, which serves a protective function when breathing is excessively depressed during sleep (Phillipson and Bowes, 1986; Davidson Ward and Keens, 1992). These are particularly interesting in the current context because serotonergic raphe neurons are implicated in both chemical control of respiration (Richerson, 1995; Nattie, 1999) and arousal mechanisms (Jacobs and Azmitia, 1992).

There is a growing literature implicating medullary serotonergic neurons of the caudal raphe as a site for respiratory chemosensitivity (for review, see Richerson, 1998; Nattie, 1999); central respiratory chemoreceptors sense changes in brain $\mathrm{pH}$ and/or $\mathrm{CO}_{2}$ and adjust the level of excitatory drive to brainstem centers that control breathing (and thus, $\mathrm{pH}$ and $\mathrm{pCO}_{2}$ ) (Nattie, 1999). In vitro studies, including the present work, indicate that serotonergic caudal raphe neurons are stimulated by changes in $\mathrm{pH}$ and/or
$\mathrm{CO}_{2}$ (Richerson, 1995; Wang and Richerson, 2000; Wang et al., 2001), and, because local acidification of the raphe region enhances respiratory output in vivo (Bernard et al., 1996), it has been proposed that these cells may indeed provide a locus for central respiratory chemoreception (Richerson, 1998; Nattie, 1999). The ionic mechanisms responsible for $\mathrm{pH}$ sensitivity of medullary raphe neurons have not been determined. A brief report suggests that a nonselective cationic conductance contributes to $\mathrm{pH}$-sensitive currents in serotonergic raphe neurons (Tiwari et al., 2000). The present data are consistent with this previous work insofar as they suggest that multiple ionic mechanisms are involved with responses to $\mathrm{pH}$ in medullary raphe neurons. In addition, our work implicates TASK channels specifically as molecular substrates for chemosensitivity of serotonergic raphe neurons, and by extension, for central respiratory chemosensitivity.

It is also noteworthy in this respect that TASK channels contribute to a $\mathrm{pH}$-sensitive increase in excitability in locus coeruleus (LC) neurons (Sirois et al., 2000), another candidate region for central respiratory chemosensitivity (Nattie, 1999; Ballantyne and Scheid, 2000), and in carotid body chemoreceptors, which provide afferent input related to arterial $\mathrm{pH}$ to medullary respiratory centers from the periphery (Buckler et al., 2000). Moreover, a direct $\mathrm{pH}$-dependent increase in excitability is attributed to TASK channels in respiratory-related motoneurons (Talley et al., 2000), which ultimately convey central respiratory drive to the muscles of breathing. Thus, the pH sensitivity of TASK channels may be exploited at multiple levels to monitor changes in prevailing acid-base status for purposes of homeostatic regulation of breathing. Of course, it is likely that other $\mathrm{pH}$-sensitive processes in different brain regions contribute also to $\mathrm{pH}$-dependent regulation of breathing (Nattie, 1999).

To date, a role for RDo neurons in regulating respiratory output in response to changes in brain $\mathrm{pH}$ has not been suggested, although it is known that a population of RDo neurons increase their firing in response to hypercapnic challenge in vivo (Veasey et al., 1997). Unlike caudal raphe neurons, which project primarily to brainstem and spinal neurons, the efferent targets of RDo neurons are primarily cell groups in rostral brain regions, and, accordingly, RDo neurons are thought to participate in a number of higher-order functions (Jacobs and Azmitia, 1992). The activity of RDo neurons in vivo is tightly coupled to sleep-wake states, an observation that has led to the suggestion that these cells have a key role in behavioral arousal (Jacobs and Azmitia, 1992). Our data indicate that modulation of TASK channels by extracellular hydrogen ions in the RDo contributes to $\mathrm{pH}$-dependent effects on excitability in these neurons, suggesting that this could serve to regulate arousal state in a $\mathrm{pH}$-dependent manner. Interestingly, the LC is another region strongly implicated in control of arousal (Aston-Jones and Bloom, 1981; Aston-Jones et al., 1991), and we found that TASK channels also contribute to increased LC neuron excitability by extracellular acidification (Sirois et al., 2000). A pH-dependent influence of TASK channels on arousal, mediated by RDo and LC neurons, may be particularly important when ventilation becomes excessively depressed during sleep and when the ensuing hypercapnia provokes the waking response necessary to reinstate appropriate levels of ventilation (Phillipson and Bowes, 1986; Davidson Ward and Keens, 1992). Activation of this arousal mechanism is responsible, at least in part, for sleep disturbances associated with obstructive apneas (Horner, 1996), and failure of this waking reflex in neonates may be a contributing 
factor to sudden infant death syndrome (Hunt, 1992; Richerson, 1997).

\section{Clinical relevance of an anesthetic-sensitive background $\mathrm{K}^{+}$current in serotonergic raphe neurons}

TASK channels are activated by inhalation anesthetics at concentrations that are entirely appropriate for clinically relevant anesthetic effects (Patel et al., 1999; Meadows and Randall, 2001). Our results indicate that halothane activates a TASK-like current in serotonergic raphe neurons, an effect that will drive membrane potential toward more hyperpolarized potentials and decrease activity during anesthesia. At least two main effects always accompany the clinical state of general anesthesia: immobilization and loss of consciousness (Eger, 1993). We suggest that anesthetic modulation of TASK channels in raphe neurons could conceivably contribute to both of these effects.

First, serotonergic medullary raphe neurons project to brainstem motor nuclei and the spinal cord ventral horn, in which 5-HT and coexpressed neuropeptides exert direct facilitatory effects on motoneurons (Rekling et al., 2000). Inhibition of raphe neurons by anesthetic activation of TASK channels will decrease release of these raphe neurotransmitters and, by disfacilitation, depress motoneuronal excitability. These effects would be supported further by anesthetic activation of TASK channels in LC (Sirois et al., 2000), which would similarly decrease facilitating effects of noradrenergic inputs onto motoneurons (Rekling et al., 2000), and also by direct effects of anesthetics acting on TASK channels in motoneurons themselves (Sirois et al., 2000). Thus, activation of TASK channels at a number of central sites may contribute to immobilizing effects of anesthetics.

As mentioned above, RDo neurons have prominent projections to rostral brain regions and a highly state-dependent firing pattern that suggests a role in behavioral arousal (Jacobs and Azmitia, 1992). Thus, a decrease in activity of these neurons mediated by TASK channels could contribute to sleep-inducing effects of anesthetics, a role we suggested previously for the TASKexpressing LC neurons (Sirois et al., 2000) that are also implicated in control of arousal (Aston-Jones and Bloom, 1981; AstonJones et al., 1991). Of course, direct effects of anesthetics on other neurons expressing TASK channels (e.g., thalamic and cortical neurons; Talley et al., 2001) could contribute to these and other clinically important actions of the drugs.

In summary, we suggest that expression of TASK channels contributes to the $\mathrm{pH}$ sensitivity of serotonergic raphe neurons and thus to respiratory and arousal reflexes associated with hypercapnia and/or acidosis (Richerson, 1998; Nattie, 1999). Activation of TASK channels in these neurons may also contribute to clinically important actions of volatile anesthetics, such as immobilization and sleep induction. Furthermore, opposing regulation of TASK channel activity by acidosis and anesthetics in serotonergic raphe neurons provides a potential mechanism that could account for the well known diminished ventilatory responses to respiratory acidosis (i.e., respiratory depression) during inhalational anesthesia (Pavlin and Hornbein, 1986). These speculations are potentially testable in genetically altered mice because mutations that disrupt either pH (Y. Kim et al., 2000; Rajan et al., 2000; Lopes et al., 2001) or anesthetic modulation (Patel et al., 1999) of otherwise normal TASK channels have been identified.

\section{REFERENCES}

Aston-Jones G, Bloom FE (1981) Activity of norepinephrine-containing locus coeruleus neurons in behaving rats anticipates fluctuations in the sleep-waking cycle. J Neurosci 1:876-886.
Aston-Jones G, Chiang C, Alexinsky T (1991) Discharge of noradrenergic locus coeruleus neurons in behaving rats and monkeys suggests a role in vigilance. Prog Brain Res 88:501-520.

Ballantyne D, Scheid P (2000) Mammalian brainstem chemosensitive neurones: linking them to respiration in vitro. J Physiol (Lond) 525:567-577.

Bayliss DA, Li YW, Talley EM (1997) Effects of serotonin on caudal raphe neurons: activation of an inwardly rectifying potassium conductance. J Neurophysiol 77:1349-1361.

Bernard DG, Li AH, Nattie EE (1996) Evidence for central chemoreception in the midline raphe. J Appl Physiol 80:108-115.

Buckler KJ, Williams BA, Honore E (2000) An oxygen-, acid- and anaesthetic-sensitive TASK-like background potassium channel in rat arterial chemoreceptor cells. J Physiol (Lond) 525:135-142.

Davidson Ward SL, Keens TG (1992) Ventilatory and arousal responses. In: Respiratory control disorders in infants And Children (Beckerman RC, Brouillette RT, Hunt CE, eds), pp 112-124. Baltimore: Williams \& Wilkins.

Decher N, Maier M, Dittrich W, Gassenhuber J, Bruggemann A, Busch AE, Steinmeyer K (2001) Characterization of TASK-4, a novel member of the $\mathrm{pH}$-sensitive, two-pore domain potassium channel family. FEBS Lett 492:84-89.

Duprat F, Lesage F, Fink M, Reyes R, Heurteaux C, Lazdunski M (1997) TASK, a human background $\mathrm{K}^{+}$channel to sense external $\mathrm{pH}$ variations near physiological pH. EMBO J 16:5464-5471.

Eger EI (1993) What is general anesthetic action? Anesth Analg 77:408-409.

Girard C, Duprat F, Terrenoire C, Tinel N, Fosset M, Romey G, Lazdunski M, Lesage F (2001) Genomic and functional characteristics of novel human pancreatic $2 \mathrm{P}$ domain $\mathrm{K}^{+}$channels. Biochem Biophys Res Commun 282:249-256.

Goldstein SAN, Bockenhauer D, O'Kelly I, Zilberberg N (2001) Potassium leak channels and the KCNK family of two-P-domain subunits. Nat Rev Neurosci 2:175-184.

Gray AT, Zhao BB, Kindler CH, Winegar BD, Mazurek MJ, Xu J, Chavez RA, Forsayeth JR, Yost CS (2000) Volatile anesthetics activate the human tandem pore domain baseline $\mathrm{K}^{+}$channel KCNK5. Anesthesiology 92:1722-1730.

Horner RL (1996) Motor control of the pharyngeal musculature and implications for the pathogenesis of obstructive sleep apnea. Sleep 19:827-853.

Hunt CE (1992) Sudden infant death syndrome. In: Respiratory control disorders in infants and children (Beckerman RC, Brouillette RT, Hunt CE, eds), pp 190-211. Baltimore: Williams \& Wilkins.

Jacobs BL, Azmitia EC (1992) Structure and function of the brain serotonin system. Physiol Rev 72:165-229.

Kim D, Gnatenco C (2001) TASK-5, a new member of the tandem-pore $\mathrm{K}^{+}$channel family. Biochem Biophys Res Commun 284:923-930.

Kim D, Fujita A, Horio Y, Kurachi Y (1998) Cloning and functional expression of a novel cardiac two-pore background $\mathrm{K}^{+}$channel (cTBAK-1). Circ Res 82:513-518.

Kim Y, Bang H, Kim D (1999) TBAK-1 and TASK-1, two-pore $\mathrm{K}^{+}$ channel subunits: kinetic properties and expression in rat heart. Am J Physiol Heart Circ Physiol 277:H1669-H1678.

Kim Y, Bang H, Kim D (2000) TASK-3, a new member of the tandem pore $\mathrm{K}^{+}$channel family. J Biol Chem 275:9340-9347.

Leonoudakis D, Gray AT, Winegar BD, Kindler CH, Harada M, Taylor DN, Chavez RA, Forsayeth JR, Yost CS (1998) An open rectifier potassium channel with two pore domains in tandem cloned from rat cerebellum. J Neurosci 18:868-877.

Lesage F, Lazdunski M (2000) Molecular and functional properties of two-pore-domain potassium channels. Am J Physiol Renal Physiol 279:F793-F801.

Lopes CMB, Gallagher PG, Buck ME, Butler MH, Goldstein SA (2000) Proton block and voltage gating are potassium-dependent in the cardiac leak channel Kcnk3. J Biol Chem 275:16969-16978.

Lopes CMB, Zilberberg N, Goldstein SA (2001) Block of Kcnk3 by protons-evidence that 2-P-domain potassium channel subunits function as homodimers. J Biol Chem 276:24449-24452.

Meadows HJ, Randall AD (2001) Functional characterisation of human TASK-3, an acid-sensitive two-pore domain potassium channel. Neuropharmacology 40:551-559.

Nattie E (1999) CO2, brainstem chemoreceptors and breathing. Prog Neurobiol 59:299-331.

Patel AJ, Honore E (2001) Properties and modulation of mammalian 2P domain $\mathrm{K}^{+}$channels. Trends Neurosci 24:339-346.

Patel AJ, Honore E, Lesage F, Fink M, Romey G, Lazdunski M (1999) Inhalational anesthetics activate two-pore-domain background $\mathrm{K}^{+}$ channels. Nat Neurosci 2:422-426.

Patel AJ, Lazdunski M, Honore E (2001) Lipid and mechano-gated 2P domain $\mathrm{K}^{+}$channels. Curr Opin Cell Biol 13:422-428.

Pavlin EG, Hornbein TF (1986) Anesthesia and the control of ventilation. In: Handbook of physiology: the respiratory system, Vol 2 (Fishman AP, Cherniack NS, Widdicombe JG, eds), pp 793-813. Bethesda, MD: American Physiological Society. 
Paxinos G, Watson C (1997) The rat brain in stereotaxic coordinates. San Diego: Academic.

Penington NJ, Kelly JS, Fox AP (1993) Whole-cell recordings of inwardly rectifying $\mathrm{K}^{+}$currents activated by $5-\mathrm{HT}_{1 \mathrm{~A}}$ receptors on dorsal raphe neurones of the adult rat. J Physiol (Lond) 469:387-405.

Phillipson EA, Bowes G (1986) Control of breathing during sleep. In: Handbook of physiology. the respiratory system, pp 649-689. Bethesda, MD: American Physiological Society.

Rajan S, Wischmeyer E, Xin LG, Preisig-Muller R, Daut J, Karschin A, Derst C (2000) TASK-3, a novel tandem pore domain acid-sensitive $\mathrm{K}^{+}$channel: an extracellular histidine as $\mathrm{pH}$ sensor. J Biol Chem 275:16650-16657.

Rekling JC, Funk GD, Bayliss DA, Dong XW, Feldman JL (2000) Synaptic control of motoneuronal excitability. Physiol Rev 80:767-852.

Reyes R, Duprat F, Lesage F, Fink M, Salinas M, Farman N, Lazdunski M (1998) Cloning and expression of a novel $\mathrm{pH}$-sensitive two pore domain $\mathrm{K}^{+}$channel from human kidney. J Biol Chem 273:30863-30869.

Richerson GB (1995) Response to $\mathrm{CO}_{2}$ of neurons in the rostral ventral medulla in vitro. J Neurophysiol 73:933-944.

Richerson GB (1997) Sudden infant death syndrome: the role of central chemosensitivity. The Neuroscientist 3:3-7.

Richerson GB (1998) Cellular mechanisms of sensitivity to $\mathrm{pH}$ in the mammalian respiratory system. In: $\mathrm{pH}$ and brain function (Kaila K, Ransom BR, eds), pp 509-533. New York: Wiley-Liss.

Sirois JE, Lei Q, Talley EM, Lynch III C, Bayliss DA (2000) The
TASK-1 two-pore domain $\mathrm{K}^{+}$channel is a molecular substrate for neuronal effects of inhalation anesthetics J Neurosci 20: 6347-6354.

Talley EM, Lei Q, Sirois JE, Bayliss DA (2000) TASK-1, a two-pore domain $\mathrm{K}^{+}$channel, is modulated by multiple neurotransmitters in motoneurons. Neuron 25: 399-410.

Talley EM, Solórzano G, Lei Q, Kim D, Bayliss DA (2001) CNS distribution of members of the two-pore-domain $(\mathrm{KCNK})$ potassium channel family. J Neurosci 21:7491-7505.

Tiwari JK, Zaykin AV, Cruadhlaoich MI, Wang W, Richerson GB (2000) A novel pH sensitive cation current is present in putative central chemoreceptors of the medullary raphe. Soc Neurosci Abstr 26:423.

Veasey SC, Fornal CA, Metzler CW, Jacobs BL (1997) Single-unit responses of serotonergic dorsal raphe neurons to specific motor challenges in freely moving cats. Neuroscience 79:161-169.

Vega-Saenz DM, Lau DH, Zhadina M, Pountney D, Coetzee WA, Rudy B (2001) Kt3.2, kt3.3, two novel human two-pore $\mathrm{K}^{+}$channels closely related to TASK-1. J Neurophysiol 86:130-142.

Wang W, Richerson GB (2000) Chemosensitivity of non-respiratory rat CNS neurons in tissue culture. Brain Res 860:119-129.

Wang WG, Tiwari JK, Bradley SR, Zaykin AV, Richerson GB (2001) Acidosis-stimulated neurons of the medullary raphe are serotonergic. J Neurophysiol 85:2224-2235.

Watson Jr RE, Wiegand SJ, Clough RW, Hoffman GE (1986) Use of cryoprotectant to maintain long-term peptide immunoreactivity and tissue morphology. Peptides 7:155-159. 